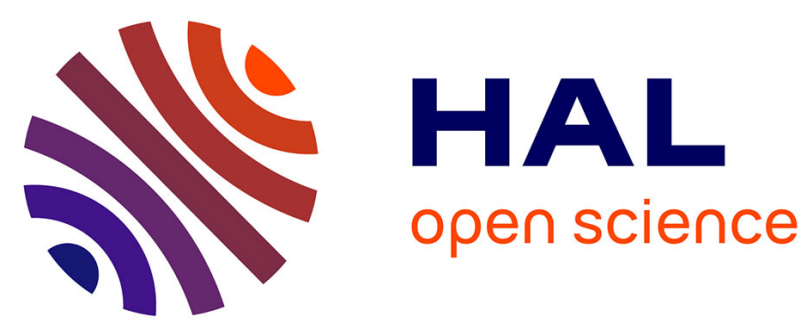

\title{
Chromosomal translocations and semen quality: A study on 144 male translocation carriers
}

Anne Mayeur, Naouel Ahdad, Laetitia Hesters, Sophie Brisset, Serge Romana, Lucie Tosca, Gérard Tachdjian, Nelly Frydman

\section{To cite this version:}

Anne Mayeur, Naouel Ahdad, Laetitia Hesters, Sophie Brisset, Serge Romana, et al.. Chromosomal translocations and semen quality: A study on 144 male translocation carriers. Reproductive BioMedicine Online, 2019, 38, pp.46 - 55. 10.1016/j.rbmo.2018.10.003 . hal-03486389

\section{HAL Id: hal-03486389 \\ https://hal.science/hal-03486389}

Submitted on 20 Dec 2021

HAL is a multi-disciplinary open access archive for the deposit and dissemination of scientific research documents, whether they are published or not. The documents may come from teaching and research institutions in France or abroad, or from public or private research centers.
L'archive ouverte pluridisciplinaire HAL, est destinée au dépôt et à la diffusion de documents scientifiques de niveau recherche, publiés ou non, émanant des établissements d'enseignement et de recherche français ou étrangers, des laboratoires publics ou privés.

\section{(ㄷ)(1) $\$$}

Distributed under a Creative Commons Attribution - NonCommerciall 4.0 International 


\section{Chromosomal translocations and semen quality: a study on 144 male translocation carriers}

Anne Mayeur ${ }^{a}$, , Naouel Ahdad b , Laetitia Hesters ${ }^{a}$, Sophie Brisset c, Serge Romana ${ }^{d}$, Lucie Tosca c, Gérard Tachdjian ' , Nelly Frydman a

a AP-HP, Reproductive Biology Unit, Paris-Sud University, Paris-Saclay University, Antoine Béclère Hospital, Clamart 92140, France; ${ }^{\mathrm{b}}$ AP-HP, Reproductive Medicine Unit, Paris-Sud University, Paris-Saclay University, Antoine Béclère Hospital, Clamart 92140, France; ' AP-HP, Cytogenetic Unit, Paris-Sud University, Paris-Saclay University, Antoine Béclère Hospital, Clamart 92140, France; d AP-HP, Cytogenetic Unit, Paris Descartes University, Necker-Enfants-Malades Hospital, Paris 75015, France

* Corresponding author. E-mail address: anne.mayeur@aphp.fr (A Mayeur).

\section{Abstract}

Research question: Chromosomal translocations are known genetic causes of male infertility. Are certain translocations or chromosomal regions more directly associated with sperm defects? Is there a threshold of sperm impairment that can be relevant for detection of translocations?

Design: This is a monocentric retrospective observational study covering a 10 -year period. Eighty-one patients carrying a reciprocal translocation (RCT) and 63 carrying a Robertsonian translocation (ROBT) were compared with 105 fertile patients. Semen quality before and after sperm migration was compared. The aims were to define whether a threshold based on sperm analysis could be proposed for detection of translocations and to identify whether some redundant chromosomal regions might be associated with sperm quality defects.

Results: The number of progressive spermatozoa retrieved after sperm preparation (NPS-ASP) was altered in both RCT and ROBT carriers compared with controls, with a stronger alteration in ROBT. Based on the NPS-ASP results in this large group of translocation carriers, a relatively robust threshold, fixed at less than 5 million, may be proposed for detection of translocations. The alteration of NPS-ASP was independent of the chromosome involved in ROBT, while in RCT, four redundant chromosomal regions (1q21,6p21, 16q21, 17q11.2) were associated with poor or very poor NPS-ASP.

Conclusions: The NPS-ASP appears to be a good parameter to assess sperm function and would be a useful tool to detect chromosomal translocations. Four redundant regions have been identified on four chromosomes, suggesting that they may contain genes of interest to study sperm functions.

\section{Key message}

Semen quality is altered in patients bearing a chromosomal translocation, especially in cases of Robertsonian translocation. In reciprocal translocation carriers, four chromosomal regions were identified with a redundant deleterious effect on semen quality.

Keywords: chromosomal translocation; karyotype; male infertility; semen quality 


\section{Introduction}

Chromosomal translocations are the most common structural chromosomal rearrangements observed in humans, with a frequency of 1.23 per thousand (Nielsen and Wohlert, 1991). Among them, Robertsonian translocations (ROBT) are the most common (Therman and Susman, 2012). This rearrangement occurs when the complete long arms of two homologous or non-homologous acrocentric chromosomes $(13,14,15,21$ or 22$)$ fuse while the short arms of the translocated chromosomes are lost. The distribution of different ROBT in the general population is non-random, with the $\operatorname{rob}(13 ; 14)$ and $\operatorname{rob}(14 ; 21)$ translocations constituting $\sim 85 \%$ of all ROBT. Other ROBT, such as $\operatorname{rob}(14 ; 22), \operatorname{rob}(15 ; 21)$ and $\operatorname{rob}(13 ; 15)$ are considered to be rare and constitute the remaining $\sim 15 \%$ of these translocations (Therman et al., 1989). The other most common chromosomal abnormality is reciprocal translocation (RCT), which occurs when there is an exchange between two broken arms of two non-homologous chromosomes.

During meiosis, homologous chromosomes pair, synapse and recombine; these steps are crucial for correct chromosomal segregation and gamete production. In the case of balanced translocation, the abnormal behaviour of the rearranged autosomes in meiosis leads to chromosomal malsegregation and to generation of unbalanced spermatozoa (Benet et al., 2005; Frydman et al., 2001; Gabriel-Robez et al., 1986; Luciani et al., 1984; Piomboni et al., 2014; Rosenmann et al., 1985; Van Assche et al., 1996). Apart from the chromosomal unbalanced risk associated with chromosomal rearrangements, interchromosomal effects may increase the occurrence of nondisjunction of chromosomes not involved in translocations (Douet-Guilbert et al., 2005).

The prevalence of chromosomal abnormalities is higher in infertile men and the overall incidence of a chromosomal factor in infertile males ranges between $2 \%$ and $8 \%$, with a mean value of $5 \%$ (Ferlin et al., 2007).

Alteration of semen quality in male translocation carriers may be due to varying degrees of spermatogenic breakdown related to meiotic disturbance and failure in gamete production (Chandley et al., 1972; Douet-Guilbert et al., 2005; Egozcue et al., 2000; Ferlin et al., 2007; Shah et al., 2003; Van Assche et al., 1996). Chromosomal structural rearrangement may have different impacts on individuals and there may be a different effect on the testes. Most of the published studies investigating the relationship between semen quality and balanced chromosomal rearrangement were based on analysis of men who have suffered infertility (Dong et al., 2012; Elfateh et al., 2014; H. G. Zhang et al., 2015; Xie et al., 2017). Although their initial cohorts were large in number, chromosomal rearrangements were diagnosed in only a small number of cases.

The objectives of the present study, based on a 10-year period in practising preimplantation genetic testing (PGT) for male translocations, were: (i) to compare the sperm characteristics in 144 translocation carriers and 105 control men, (ii) to identify whether a threshold based on sperm analysis can be proposed for detection of translocations, and (iii) to analyse semen quality according to the chromosomes involved, in order to better characterize whether one of the chromosomes particularly contributes to poor semen parameters. 


\section{Materials and methods}

The present study is a monocentric retrospective observational study carried out from 2007 to 2016. Consent from all participants was obtained at the time of the semen collection for the use of their medical data in view of research. The database was approved by the National Data Protection Authority (Commission Nationale de I'Informatique et des Libertés, CNIL no. 1217921) on 21 February 2007. According to the 'Jardé Law' (decree no. 2016-1537, 16 November 2016), Institutional Review Board approval was not required for this retrospective study.

\section{Patients}

One hundred and forty-four men referred to the author's Centre for PGT (Centre Béclère Necker hospitals) for a male chromosomal translocation were studied. In 81 patients, a de novo or familial RCT had been detected through standard karyotyping. The two-break chromosomal rearrangement had been identified by specific DNA probes using fluorescence in-situ hybridization (FISH). The 63 other patients were characterized as ROBT carriers identified through standard karyotyping.

As a control, 105 fathers enrolled in PGT for a monogenic disease were selected from couples that had already suffered from the medical termination of pregnancy or already had a healthy or affected child. Control men benefited from the same treatment as the studied group over the same period in the same hospital. Sperm provision was carried out in the same place with the same therapeutic purpose: benefit from a PGT. It can therefore be proposed that overall, patients experienced the same stress. Moreover, the number of days of sexual abstinence was controlled in the control and studied groups. Given the aim of this study, it was important to compare the treatment group to a control with a known, normal karyotype. Because it is systematically performed before PGT, the selection of PGT-father candidates was particularly appropriate.

\section{Semen analysis}

Fresh semen samples were collected for IVF/intra-cytoplasmic sperm injection (ICSI) prior to the PGT attempt by masturbation after 3-5 days of sexual abstinence. The overall semen samples were treated in the same laboratory. They were incubated at $37^{\circ} \mathrm{C}$ and analysed within $1 \mathrm{~h}$ using a manual method according to the World Health Organization guidelines (WHO Laboratory Manual for the Examination and Processing of Human Semen, 2010). Over the 10-year period of this study, seven trained technicians regularly evaluated sperm parameters for intra- or inter-variability. There were no significant changes in laboratory variables: neither in the conditions for evaluating sperm parameters nor in the media or consumables used. Initial sperm concentrations $\left(\times 10^{6}\right.$ per $\mathrm{ml}$ ) were assessed using a hemocytometric method (Malassez chamber) by counting at least 100 spermatozoa. The total number of spermatozoa per ejaculate $\left(\times 10^{6}\right)$, grossly reflecting testicular sperm production, was calculated as the product of sperm concentration and the volume of seminal fluid. The percentage of progressively motile spermatozoa was assessed at $37^{\circ} \mathrm{C}$, at $\times 100$ and $\times 400$ magnification with phase optics in four to six fields, chosen at random from two preparations, and the mean value being reported. Liquefied ejaculate was dropped into a discontinuous Pure Sperm (Nidacom, JCD, France) preparation (45\% and 90\%) and the sperm pellet was washed in Ferticult medium (FertiPro NV, JCD, France) by centrifugation at $600 \mathrm{~g}$ for $10 \mathrm{~min}$. Final sperm concentration and progressive motility were assessed as already described in the resuspended sperm pellet. The total number of progressive spermatozoa retrieved after sperm preparation (NPS-ASP) was 
calculated for each patient from the total number of spermatozoa and the percentage of progressively motile cells. NPS-ASP is considered of biological importance for assisted reproductive technologies because it determines the potential use of spermatozoa through intrauterine insemination (IUI), conventional IVF or ICSI. It was therefore decided to use NPS-ASP as a marker of sperm quality. In this study, NPSASP has been categorized as good, fair, poor, and very poor according to the minimal NPS-ASP required for each technique: good ( $\geq 5 \times 10^{6}$ for IUI); fair ( $>1 \times 10^{6}$ to $\left.<5 \times 10^{6}\right)$ for IVF, poor $\left(>0.5 \times 10^{6}\right.$ to $\left.\leq 1 \times 10^{6}\right)$, and very poor $\left(\leq 0.5 \times 10^{6}\right)$ for ICSI.

\section{Standard karyotyping and FISH}

Standard chromosomal analyses were performed on cultured peripheral lymphocytes from the patient using standard procedures [G-banding with Trypsin using Giemsa (GTG); R-banding after Heat denaturation and Giemsa (RHG)]. FISH analyses were performed on metaphase spreads of lymphocytes from the patient. In accordance with breakpoints visualized on a standard karyotype, specific DNA probes were used, following the manufacturer's recommendations (Vysis-Abbott, Suresnes, France), to identify chromosome segments involved in translocation.

Statistical analysis

Statistical analyses were performed using GraphPad Prism (ver. 5.02, Graphpad Software Inc., San Diego, CA, USA). An unpaired t-test was used to compare the three patient groups and to test for differences. When $P<0.05$, the difference was considered statistically significant. The distances from the breakpoints to centromere of both chromosomes involved in each translocation were summed and tested for an eventual correlation with NPS-ASP using a Spearman test.

The percentage of normozoospermic men according to WHO reference values ( $\geq 39 \times 10^{6}$ per ejaculate and $\geq 32 \%$ of progressive motility; Cooper et al., 2010), excluding morphology (Auger et al., 2016), was calculated in order to appreciate the number of men with an acceptable fertility potential for the comparison of ROBT and RCT carriers and fertile men.

Furthermore, patients were stratified according to their translocation into NPS-ASP categories. Finally, a whole genome view of estimated chromosomal breakpoints according to the NPS-ASP was evaluated by comparison with previously established structural classifications (karyogram). Additionally, results were classified using the classic karyotype structural groups (ISCN, 2016). These morphologic classifications (Groups $A-G$ ) are generally correlated with size and configuration in most classes. Group A included chromosomes 1-3, B chromosomes 4-5, C chromosomes 6-12 and the $\mathrm{X}$ chromosome, D chromosomes 13-15, E chromosomes 16-18, F chromosomes 19-20, and $G$ chromosomes 21-22 and the $Y$ chromosome. Mostly, this classification would give some groups more chances of having a negative effect on the NPS-ASP.

Results

The mean age of RCT and ROBT carriers ( $35.8 \pm 5.1$ and $35.7 \pm 5.5$ years, respectively) was similar to that of the control group (36.1 \pm 4.7 years).

Semen quality

Median sexual abstinence was similar between RCT or ROBT carriers and the control group (Table 1). Figure 1A presents the percentage of normozoospermic patients in the three groups. Normozoospermia was observed for only $39.5 \%$ of RCT carriers, and 
$14.3 \%$ of ROBT carriers, compared with more than $94 \%$ in the control group. The WHO manual prescribes nomenclature to be used to describe semen samples with values lying outside the reference range. Normozoospermia refers to three normal sperm parameters: number, motility and morphology. However, in this study, sperm analysis was based on the semen sample used for IVF/ICSI in the PGT attempt which, as is often the case with sperm preparation for therapeutic purposes, did not include the establishment of sperm morphology. Thus, the term normozoospermia must be considered with caution.

A statistically significant lower sperm concentration $(P<0.0001)$, total sperm count $(P<0.0001)$ and progressive motility $(P<0.001$ for RCT and $P<0.0001$ for ROBT $)$ were observed for translocation groups of men studied in comparison to control groups (Table 1). Overall, ROBT carriers had the poorest semen characteristics. Notably, the level of sperm production in ROBT carriers was about one-fifth and onetenth of the level found in RCT carriers and in the control group, respectively. The NPS-ASP was altered in both RCT and ROBT carriers. Of note, this alteration was stronger in patients bearing a ROBT because $3.2 \%$ of them had a NPS-ASP categorized as good, while there was a $35.8 \%$ rate in RCT carriers (Figure 1B). Despite the alteration of semen quality that was stronger in patients bearing a ROBT, the percentage of balanced embryos obtained after PGT was more favourable in ROBT than in RCT (Supplementary Table 1).

Semen quality by chromosome classification

The proportion of good, fair, poor and very poor NPS-ASP obtained after sperm preparation for each type of ROBT is presented in Figure 2. The majority of patients $(n=53)$ bear a common ROBT $[\operatorname{rob}(13 q ; 14 q)$ or $\operatorname{rob}(14 q ; 21 q)]$ and ten carried a rare ROBT. In most cases the NPS-ASP was poor or very poor $\left(\leq 1 \times 10^{6}\right)$, independently of the chromosome involved.

Table 2 summarizes the listing of karyotypes of the overall reciprocal translocation carriers studied according to NPS-ASP values. The distances from the breakpoints to centromeres for both chromosomes involved in each reciprocal translocation are also mentioned. No significant correlation was found between any NPS-ASP and these distances $(r=0.07)$. In Supplementary Figure 1 , the NPS-ASP was spotted on an original karyogram (Supplementary Figure 1A). This representation allows us to show the NPS-ASP category for each chromosome at each breakpoint. The 'good' NPS-ASP category was distributed on all chromosomes except for chromosomes 19, 20 and 21 . For a similar breakpoint the NPS-ASP may vary from good to very poor quality (2p24; 5p15, 5q34, 6q23, 8q23, 11q22, 18q21, 22q11). Three different breakpoints occurring on $9 q$ were associated with a very poor NPS-ASP $(9 q 12,9 q 31$, 9q33). Four redundant regions were associated with poor or very poor NPS-ASP $(1 q 21,6 p 21,16 q 21,17 q 11.2)$. Patients with a very poor or poor NPS-ASP sharing the same breakpoints are marked in bold in Table 2. Relatively short or short metacentric and submetacentric chromosomes (Groups E and F) were more often associated with a poor or very poor NPS-ASP compared with other groups $(69.6 \%$ versus $34.1 \%$, $P<0.01$ ) (Supplementary Figure 1B). Twenty-eight patients carried an RCT involving an acrocentric chromosome, of them $13(46.4 \%)$ had a poor or very poor NPS-ASP, while this rate was $82.5 \%$ in ROBT patients.

\section{Discussion}

The present clinical investigation included 144 men bearing a structural chromosomal rearrangement; the first aim was to determine whether in this defined cohort, the 
semen quality was altered. The prognostic value of semen quality, as a surrogate marker of male fertility, may be confounded in several ways (Cooper et al., 2010). This is why it was important to compare the studied group with a fertile control group. However, defining which men are most suitable to be included as control remains a major challenge. The reference population used by Cooper et al. (2010) had fertile men whose partners had a time-to-pregnancy of 12 months or less. The control group had the same profile, but the time-to-pregnancy was not recorded.

It was found that semen quality was decreased in comparison with the control cohort, especially in the case of ROBT. This was in agreement with other authors (Pastuszek et al., 2015; Vozdova et al., 2013). It was also found that $40 \%$ of the RCT carriers were normozoospermic, confirming data reported by Zhang et al. (2015) in a smaller study.

One of the advantages of this study was the population recruitment method; patients were not specifically referred to the IVF clinic for male infertility, but as candidates for PGT. This recruitment provided an opportunity to study a large panel of male patients with variable semen quality. However, the present study has some limitations. Although the age and sexual abstinence between each group were similar, other confounding factors such as smoking, drinking, BMI and environmental toxic exposure were not considered. It is probable that, due to the relatively large size of the three groups, some factors will be levelled out, but it cannot be ruled out that there may be a potential bias. Another limitation may be the manual semen analysis performed. Although the laboratory was certified in 2006 (ISO 9001) and accredited in 2013 (NF 15189), the occurrence of inter- or intra-observer variability cannot be ruled out, albeit in view of the quality assurance policy in place this constitutes a minor limitation.

In this study the NPS-ASP was considered to be more relevant to assess semen quality than raw spermatozoa, as previously done by other authors (Dong et al., 2012; Elfateh et al., 2014; H. G. Zhang et al., 2015; Xie et al., 2017). Indeed, sperm migration techniques evaluate the aptitude of spermatozoa to cross the cervical mucus and the NPS-ASP represents the potential number of spermatozoa capable of reaching the oocyte in the Fallopian tube. Taking into account the NPS-ASP obtained in known fertile control patients, when it is categorized as good, it seems to be compatible with good sperm function.

It is usually accepted that the frequency of chromosomal abnormalities increases in an infertile population compared with normal fertile men (Xie et al., 2017), thus justifying the prescription of a standard male karyotype. However, this examination is expensive and not always covered by third-party payers. The second aim of this study was thus to define whether a semen quality threshold could be defined by the NPS-ASP to offer karyotyping. The American Society of Reproductive Medicine recommends that karyotyping should be offered to men who have non-obstructive azoospermia or severe oligospermia (defined as $<5 \times 10^{6} \mathrm{sperm} / \mathrm{ml}$ in raw semen) (Male Infertility Best Practice Policy Committee of the American Urological Association, and Practice Committee of the American Society for Reproductive Medicine, 2006). According to this recommendation, $50 \%$ of ROBT and most of the RCT carriers included in this study would not be detected (Table 1). For the Dutch Society of Obstetrics and Gynaecology (NVOG, 1999), male standard karyotype has to be prescribed when the total motile sperm count $<1$ million in raw semen. As before, this second recommendation appears to be insufficient to detect chromosomal abnormalities because only $14.8 \%$ of RCT and $33.3 \%$ of ROBT carriers included in this study would be detected. Others have discussed the determination of male chromosomal status 
systematically if ICSI is required (Chandley et al., 1975; Cruger et al., 2003; Tuerlings et al., 1998). In this study, $82.5 \%$ of ROBT carriers had an NPS-ASP requiring the use of ICSI, while in RCT carriers, ICSI was only required for $42 \%$ of cases. Yet, it is noteworthy that the NPS-ASP seems to be a more reliable criterion for identifying a patient bearing a chromosomal rearrangement. Indeed, with a threshold fixed at fewer than 5 million, $97 \%$ of ROBT and $75 \%$ of RCT would be detected.

The third objective of this study was to analyse semen quality according to the chromosomes involved in the chromosomal rearrangement. Several hypotheses have been proposed to explain why the chromosomal rearrangement of male carriers frequently harboured an altered semen quality. One theory originated from a mechanical mechanism: physiologically, the formation of the sex body is associated with epigenetic remodelling of the sex chromatin and transcriptional repression of $X-$ and Y-linked genes (Baarends et al., 2005; Khalil et al., 2004), resulting in a meiotic sex chromosome inactivation. In cases of translocation, it has been suggested that a gradual contact of the asynaptic region of trivalent (ROBT) or quadrivalent (RCT) with the transcriptional inactive $X Y$ body throughout the long pachytene stage may disturb meiotic sex chromosome inactivation (Gabriel-Robez and Rumpler, 1996; Lifschytz and Lindsley, 1972; Sciurano et al., 2007). In the specific case of ROBT, the heterochromatic short arms of acrocentric chromosomes carry the nucleolar organizer regions (NOR) which, in addition to their function in rRNA synthesis, are required to associate with the sex vesicle. Thus, ROBT that have lost their NOR can increase the likelihood of cell disruption and germ cell death, thus decreasing fertility (Antonelli et al., 2000; Gabriel-Robez and Rumpler, 1996; Shah et al., 2003). Page et al. (1996) revealed that highly variable locations of breakpoints may occur in the less common ROBT, whilst for common ROBT such as (13q14q) and (14q21q) the region where the breakpoints are localized are the same. This was confirmed more recently (JarmuzSzymczak et al., 2014). This may be a plausible argument to explain why patients bearing a common ROBT may present similar meiotic segregation patterns leading to an alteration of semen quality. However, whether chromosomal rearrangement may affect meiosis was not investigated in the present study because none of the patients underwent testicular sperm extraction. The altered NPS-ASP in the vast majority of (13q14q) carriers included in this study supports this hypothesis. Another hypothesis is that chromosomal breakpoints may result in the disruption of a gene required for spermatogenesis. In a mouse model, it has been shown that 388 genes are involved in spermatogenesis (Massart et al., 2012). For some, their correspondence with human infertility has already been investigated (Javadian-Elyaderani et al., 2016; Khosronezhad et al., 2015; Ren et al., 2015; Robay et al., 2018). Recently, the transcriptomic analyses of successive germ cell subtypes during human spermatogenesis revealed dynamic transcription of over 4000 genes (Jan et al., 2017), leading to a very large number of candidates to explain the genetic origin of human male infertility.

Thus, scrutinizing translocation breakpoints may be of great interest. An original karyogram for RCT carriers was constructed in this study, indicating for each chromosomal breakpoint the correspondent NPS-ASP category. It was hoped to identify in this way redundant chromosomal regions more often associated with altered semen quality and pointing to a candidate region. First, it was found that for similar breakpoints, the NPS-ASP varies from good to very poor quality $(2 \mathrm{p} 24,5 \mathrm{p} 15$, $5 q 34,6 q 23,8 q 23,11 q 22,18 q 21,22 q 11)$, excluding these regions of potential interest.

Interestingly, four redundant regions were identified on certain chromosomes as in $1 q 21,6 p 21,16 q 21,17 q 11.2$ associated with poor or very poor NPS-ASP, suggesting 
that these regions may contain a gene of interest (Table $\mathbf{2}$ and Supplementary Figure 1A). In the four chromosomal regions identified with a redundant deleterious effect on semen quality, 419 genes were referenced, of which 324 were listed in the OMIM $^{\circledR}$ database (https://www.omim.org). A total of 171 genes were identified at breakpoint 1q21, including four already reported in the literature, with a role in oocyte meiotic maturation, spermiogenesis, sperm capacitation or sperm motility. Similarly, 87 genes were identified at breakpoint 6p21, among which two are involved in sperm motility and spermatogonial proliferation. At breakpoint 16q21, of the 29 genes identified, only one has been described in the literature. This gene is less expressed in the seminal fluid in the case of asthenozoospermia. Finally, at the breakpoint 17q11.2, 59 genes were identified, of which two are involved in germ cell apoptosis regulation or acrosome function (Supplementary Table 2 ).

In conclusion, this study reports a stronger alteration of semen quality in ROBT than in RCT carriers. The number of progressive spermatozoa retrieved after sperm preparation appears to be a good parameter to assess sperm function and would be a useful tool to detect chromosomal translocations. A relatively robust threshold fixed under 5 million is proposed. Finally, four redundant regions have been identified on four chromosomes $(1,6,16$ and 17$)$, suggesting they might contain genes of interest.

\section{Acknowledgements}

The authors are grateful to patients for allowing the use of their medical files, and thank all the technical laboratory members of the Reproductive Biology Unit of Antoine Béclère Hospital.

\section{References}

Antonelli, A., L. Gandini, P. Petrinelli, L. Marcucci, R. Elli, F. Lombardo, F. Dondero, A. Lenzi. 2000. Chromosomal Alterations and Male Infertility. Journal of Endocrinological Investigation 23 (10).

Auger, J., N. Sermondade, F. Eustache. 2016. Semen Quality of 4480 Young Cancer and Systemic Disease Patients: Baseline Data and Clinical Considerations. Basic and Clinical Andrology 26: 3.

Baarends, Willy M., Evelyne Wassenaar, Roald van der Laan, Jos Hoogerbrugge, Esther Sleddens-Linkels, Jan H. J. Hoeijmakers, Peter de Boer, J. Anton Grootegoed. 2005. Silencing of Unpaired Chromatin and Histone H2A Ubiquitination in Mammalian Meiosis. Molecular and Cellular Biology 25 (3): 1041-53.

Bansal, Sandeep Kumar, Nishi Gupta, Satya Narayan Sankhwar, Singh Rajender. 2015. Differential Genes Expression between Fertile and Infertile Spermatozoa Revealed by Transcriptome Analysis. PloS One 10 (5): e0127007.

Benet, J., M. Oliver-Bonet, P. Cifuentes, C. Templado, J. Navarro. 2005. Segregation of Chromosomes in Sperm of Reciprocal Translocation Carriers: A Review. Cytogenetic and Genome Research 111 (3-4): 281-90.

Chandley, A. C., S. Christie, J. Fletcher, A. Frackiewicz, P. A. Jacobs. 1972. Translocation Heterozygosity and Associated Subfertility in Man. Cytogenetics 11 (6): 516-33.

Chandley, A. C., P. Edmond, S. Christie, L. Gowans, J. Fletcher, A. Frackiewicz, M. Newton. 1975. Cytogenetics and Infertility in Man. I. Karyotype and Seminal Analysis: Results of a Five-Year Survey of Men Attending a Subfertility Clinic Annals of Human Genetics 39 (2): 231-54.

Christensen, Greg L., Ivaylo P. Ivanov, Stephen P. Wooding, John F. Atkins, Anna Mielnik, Peter N. Schlegel, Douglas T. Carrell. 2006. Identification of Polymorphisms and Balancing Selection in the Male Infertility Candidate Gene, Ornithine Decarboxylase Antizyme 3. BMC Medical Genetics 7: 27.

Cooper, Trevor G., Elizabeth Noonan, Sigrid von Eckardstein, Jacques Auger, H. W. Gordon Baker, Hermann M. Behre, Trine B. Haugen, Thinus Kruger, Christina Wang, Michael T. Mbizvo, Kirsten M. Vogelsong. 2010. World Health Organization Reference Values for Human Semen Characteristics. Human Reproduction Update 16 (3): 231-45.

Cruger, D. G., I. Agerholm, L. Byriel, J. Fedder, G. Bruun-Petersen. 2003. Genetic Analysis of Males from Intracytoplasmic Sperm Injection Couples. Clinical Genetics 64 (3): 198-203.

Décret n²016-1537 du 16 novembre 2016 relatif aux recherches impliquant la personne humaine. Journal Officiel de la République Française. Texte $n^{\circ} 27$. 
Dong, Y., R.-C. Du, Y.-T. Jiang, J. Wu, L.-L. Li, R.-Z. Liu. 2012. Impact of Chromosomal Translocations on Male Infertility, Semen Quality, Testicular Volume and Reproductive Hormone Levels. The Journal of International Medical Research 40 (6): 2274-83.

Douet-Guilbert, N., M.-J. L. Bris, V. Amice, C. Marchetti, B. Delobel, J. Amice, M. D. Braekeleer, F. Morel. 2005. Interchromosomal Effect in Sperm of Males with Translocations: Report of 6 Cases and Review of the Literature. International Journal of Andrology 28 (6): 372-79.

Egozcue, S., J. Blanco, J. M. Vendrell, F. García, A. Veiga, B. Aran, P. N. Barri, F. Vidal, J. Egozcue. 2000. Human Male Infertility: Chromosome Anomalies, Meiotic Disorders, Abnormal Spermatozoa and Recurrent Abortion. Human Reproduction Update 6 (1): 93-105.

Elfateh, Fadlalla, Ruixue Wang, Zhihong Zhang, Yuting Jiang, Shuang Chen, Ruizhi Liu. 2014. Influence of Genetic Abnormalities on Semen Quality and Male Fertility: A Four-Year Prospective Study. Iranian Journal of Reproductive Medicine 12 (2): 95-102.

Ferlin, Alberto, Florina Raicu, Valentina Gatta, Daniela Zuccarello, Giandomenico Palka, Carlo Foresta. 2007. Male Infertility: Role of Genetic Background. Reproductive Biomedicine Online 14 (6): 734 $-45$.

Frydman, N., S. Romana, M. Le Lorc'h, M. Vekemans, R. Frydman, G. Tachdjian. 2001. Assisting Reproduction of Infertile Men Carrying a Robertsonian Translocation. Human Reproduction 16 (11): 2274-77.

Gabriel-Robez, O., C. Ratomponirina, B. Dutrillaux, F. Carré-Pigeon, Y. Rumpler. 1986. Meiotic Association between the XY Chromosomes and the Autosomal Quadrivalent of a Reciprocal Translocation in Two Infertile Men, 46,XY,t $(19 ; 22)$ and 46, XY, t $(17 ; 21)$. Cytogenetics and Cell Genetics 43 (3-4): 154-60.

Gabriel-Robez, O., Y. Rumpler. 1996. The Meiotic Pairing Behaviour in Human Spermatocytes Carrier of Chromosome Anomalies and Their Repercussions on Reproductive Fitness. II. Robertsonian and Reciprocal Translocations. A European Collaborative Study. Annales De Genetique 39 (1): 1725.

Ike, Akiko, Shuich Yamada, Hiromitsu Tanaka, Yoshitake Nishimune, Masami Nozaki. 2002. Structure and Promoter Activity of the Gene Encoding Ornithine Decarboxylase Antizyme Expressed Exclusively in Haploid Germ Cells in Testis (OAZt/Oaz3). Gene 298 (2): 183-93.

ISCN (2016): An International System for Human Cytogenetic Nomenclature, L.G.Shaffer, J.McGowanjordan, M.Schmid (eds); S.Karger,Basel. 2013.

Iyibozkurt, Ahmet Cem, Pelin Balcik, Sibel Bulgurcuoglu, Burcu Kardaş Arslan, Rükset Attar, Erkut Attar. 2009. Effect of Vascular Endothelial Growth Factor on Sperm Motility and Survival. Reproductive Biomedicine Online 19 (6): 784-88.

Jan, S. Z., T. L. Vormer, A. Jongejan, M. Röling, S. J. Silber, D. G. de Rooij, G. Hamer, S. Repping, A. M. M. van Pelt. 2017. Unraveling Transcriptome Dynamics in Human Spermatogenesis. Development .

Jarmuz-Szymczak, Malgorzata, Joanna Janiszewska, Krzysztof Szyfter, Lisa G. Shaffer. 2014. Narrowing the Localization of the Region Breakpoint in Most Frequent Robertsonian Translocations. Chromosome Research: An International Journal on the Molecular, Supramolecular and Evolutionary Aspects of Chromosome Biology 22 (4): 517-32.

Javadian-Elyaderani, Soudabeh, Kamran Ghaedi, Marziyeh Tavalaee, Farzaneh Rabiee, Mohammad Reza Deemeh, Mohammad Hossein Nasr-Esfahani. 2016. Diagnosis of Genetic Defects through Parallel Assessment of PLC $\zeta$ and CAPZA3 in Infertile Men with History of Failed Oocyte Activation. Iranian Journal of Basic Medical Sciences 19 (3): 281-89.

Khalil, Ahmad M., Fatih Z. Boyar, Daniel J. Driscoll. 2004. Dynamic Histone Modifications Mark Sex Chromosome Inactivation and Reactivation during Mammalian Spermatogenesis. Proceedings of the National Academy of Sciences of the United States of America 101 (47): 16583-87.

Khosronezhad, Nahid, Abasalt Hosseinzadeh Colagar, Seyed Mohsen Mortazavi. 2015. The Nsun7 (A11337)-Deletion Mutation, Causes Reduction of Its Protein Rate and Associated with Sperm Motility Defect in Infertile Men . Journal of Assisted Reproduction and Genetics 32 (5): 807-15.

Laflamme, Julie, Ali Akoum, Pierre Leclerc. 2005. Induction of Human Sperm Capacitation and Protein Tyrosine Phosphorylation by Endometrial Cells and Interleukin-6. Molecular Human Reproduction 11 (2): 141-50.

Lifschytz, E., D. L. Lindsley. 1972. The Role of X-Chromosome Inactivation during Spermatogenesis (Drosophila-Allocycly-Chromosome Evolution-Male Sterility-Dosage Compensation). Proceedings of the National Academy of Sciences of the United States of America 69 (1): 182 86.

Lu, Ningxia, Kevin M. Sargent, Debra T. Clopton, William E. Pohlmeier, Vanessa M. Brauer, Renee M. McFee, John S. Weber, Napoleone Ferrara, David W. Silversides, Andrea S. Cupp. 2013. Loss of Vascular Endothelial Growth Factor A (VEGFA) Isoforms in the Testes of Male Mice Causes Subfertility, Reduces Sperm Numbers, and Alters Expression of Genes That Regulate Undifferentiated Spermatogonia. Endocrinology 154 (12): 4790-4802. 
Luciani, J. M., M. R. Guichaoua, A. Mattei, M. R. Morazzani. 1984. Pachytene Analysis of a Man with a $13 q ; 14 q$ Translocation and Infertility. Behaviour of the Trivalent and Nonrandom Association with the Sex Vesicle. Cytogenetics and Cell Genetics 38 (1): 14-22.

Lue, Yanhe, Sinha Hikim, Amiya P, Christina Wang, Andrew Leung, Ronald S. Swerdloff. 2003. Functional Role of Inducible Nitric Oxide Synthase in the Induction of Male Germ Cell Apoptosis, Regulation of Sperm Number, and Determination of Testes Size: Evidence from Null Mutant Mice. Endocrinology 144 (7): 3092-3100.

Male Infertility Best Practice Policy Committee of the American Urological Association, and Practice Committee of the American Society for Reproductive Medicine. 2006. Report on Optimal Evaluation of the Infertile Male. Fertility and Sterility 86 (5 Suppl 1): S202-209.

Massart, Annelien, Willy Lissens, Herman Tournaye, Katrien Stouffs. 2012. Genetic causes of spermatogenic failure. Asian Journal of Andrology 14 (1): 40-48.

Matthews, Lauren M., Janice P. Evans. 2014. a-Endosulfine (ENSA) Regulates Exit from Prophase I Arrest in Mouse Oocytes. Cell Cycle (Georgetown, Tex.) 13 (10): 1639-49.

Nayernia, Karim, Ibrahim M. Adham, Elke Burkhardt-Göttges, Jürgen Neesen, Mandy Rieche, Stephan Wolf, Ulrich Sancken, Kenneth Kleene, Wolfgang Engel. 2002. Asthenozoospermia in Mice with Targeted Deletion of the Sperm Mitochondrion-Associated Cysteine-Rich Protein (Smcp) Gene. Molecular and Cellular Biology 22 (9): 3046-52.

Nayernia, K., A. Meinhardt, B. Drabent, I. M. Adham, C. Müller, M. Steckel, U. Sancken, W. Engel. 2003. Synergistic Effects of Germ Cell Expressed Genes on Male Fertility in Mice. Cytogenetic and Genome Research 103 (3-4): 314-20.

Nayernia, Karim, Mihaela Diaconu, Gerhard Aumüller, Gunther Wennemuth, Iris Schwandt, Kenneth Kleene, Hartmut Kuehn, Wolfgang Engel. 2004. Phospholipid Hydroperoxide Glutathione Peroxidase: Expression Pattern during Testicular Development in Mouse and Evolutionary Conservation in Spermatozoa. Molecular Reproduction and Development 67 (4): 458-64.

Nayernia, Karim, Birgit Drabent, Andreas Meinhardt, Ibrahim M. Adham, Iris Schwandt, Christian Müller, Ulrich Sancken, Kenneth C. Kleene, Wolfgang Engel. 2005. Triple Knockouts Reveal Gene Interactions Affecting Fertility of Male Mice. Molecular Reproduction and Development 70 (4): 406-16.

Nielsen, J., M. Wohlert. 1991. Chromosome Abnormalities Found among 34,910 Newborn Children: Results from a 13-Year Incidence Study in Arhus, Denmark. Human Genetics 87 (1): 81-83.

NVOG (Dutch Society of Obstetrics and Gynaecology). 1999. Guideline: assessment and treatment for male subfertility. NVOG-richtlijn nr.1999; 17:1-5. Available online: http//nvogdocumenten.nl/uploaded/docs/17_onder_behan_mannesub.pdf (7 September 2010, date last accessed).

Page, Scott L., Jong-Chul Shin, Jin-Yeong Han, Andy Choo, K. H, Lisa G. Shaffer. 1996. Breakpoint Diversity Illustrates Distinct Mechanisms for Robertsonian Translocation Formation. Human Molecular Genetics 5 (9): 1279-88.

Pastuszek, Ewa, Jolanta Kiewisz, Patrycja M. Kulwikowska, Mariusz Lukaszuk, Krzysztof Lukaszuk. 2015. Sperm Parameters and DNA Fragmentation of Balanced Chromosomal Rearrangements Carriers ». Folia Histochemica Et Cytobiologica / Polish Academy of Sciences, Polish Histochemical and Cytochemical Society 53 (4): 314-21.

Piomboni, Paola, Anita Stendardi, Laura Gambera. 2014. Chromosomal Aberrations and Aneuploidies of Spermatozoa. In Genetic Damage in Human Spermatozoa, 27-52. Advances in Experimental Medicine and Biology. Springer, New York, NY.

Prendergast, Deborah, Kathryn J. Woad, Lawrence W. Chamley, Olivia J. Holland, Andrew N. Shelling. 2014. SPACA3 Gene Variants in a New Zealand Cohort of Infertile and Fertile Couples. Human Fertility (Cambridge, England) 17 (2): 106-13.

Ren, H. Y., R. Zhong, X. P. Ding, Z. Y. Chen, Y. L. Jing. 2015. Investigation of Polymorphisms in Exon7 of the NSUN7 Gene among Chinese Han Men with Asthenospermia. Genetics and Molecular Research: GMR 14 (3): 9261-68.

Robay, Amal, Saleha Abbasi, Ammira Akil, Haitham El-Bardisi, Mohamed Arafa, Ronald G. Crystal, Khalid A. Fakhro. 2018. A systematic review on the genetics of male infertility in the era of nextgeneration sequencing. Arab Journal of Urology, Updates in Male Factor Infertility, 16 (1): 53 64.

Rosenmann, A., J. Wahrman, C. Richler, R. Voss, A. Persitz, B. Goldman. 1985. Meiotic Association between the $X Y$ Chromosomes and Unpaired Autosomal Elements as a Cause of Human Male Sterility. Cytogenetics and Cell Genetics 39 (1): 19-29.

Sargent, Kevin M., Debra T. Clopton, Ningxia Lu, William E. Pohlmeier, Andrea S. Cupp. 2016. VEGFA Splicing: Divergent Isoforms Regulate Spermatogonial Stem Cell Maintenance. Cell and Tissue Research 363 (1): 31-45.

Sciurano, R., M. Rahn, G. Rey-Valzacchi, A. J. Solari. 2007. The asynaptic chromatin in spermatocytes of translocation carriers contains the histone variant $\mathrm{Y}-\mathrm{H} 2 \mathrm{AX}$ and associates with the XY body. Human Reproduction 22 (1): 142-50. 
Shah, K., G. Sivapalan, N. Gibbons, H. Tempest, D. K. Griffin. 2003. The Genetic Basis of Infertility. Reproduction 126 (1): 13-25.

Therman, E., B. Susman, C. Denniston. 1989. The Nonrandom Participation of Human Acrocentric Chromosomes in Robertsonian Translocations. Annals of Human Genetics 53 (1): 49-65.

Therman, Eeva, Millard Susman. 2012. Human Chromosomes: Structure, Behaviour, and Effects. Springer Science and Business Media.

Tian, Ruhui, Shi Yang, Yong Zhu, Shasha Zou, Peng Li, Junlong Wang, Zijue Zhu, Yiran Huang, Zuping He, Zheng Li. 2016. VEGF/VEGFR2 Signaling Regulates Germ Cell Proliferation in vitro and Promotes Mouse Testicular Regeneration in vivo. Cells, Tissues, Organs 201 (1): 1-13.

Tokuhiro, Keizo, Ayako Isotani, Sadaki Yokota, Yoshihisa Yano, Shigeru Oshio, Mika Hirose, Morimasa Wada, Kyoko Fujita, Yukiko Ogawa, Masaru Okabe, Yoshitake Nishimune, Hiromitsu Tanaka.2009. OAZ-t/OAZ3 Is Essential for Rigid Connection of Sperm Tails to Heads in Mouse. PLoS Genetics 5 (11): e1000712.

Tuerlings, J. H., H. F. de France, A. Hamers, R. Hordijk, J. O. Van Hemel, K. Hansson, J. M. Hoovers, K. Madan, M. Van Der Blij-Philipsen, KBJ Gerssen-Schoorl, JAM Kremer and DFCM Smeets. 1998. Chromosome Studies in 1792 Males Prior to Intra-Cytoplasmic Sperm Injection: The Dutch Experience. European Journal of Human Genetics: EJHG 6 (3): 194-200.

Van Assche, E., M. Bonduelle, H. Tournaye, H. Joris, G. Verheyen, P. Devroey, A. Van Steirteghem, et I. Liebaers. 1996. Cytogenetics of infertile men. Human Reproduction 11 (suppl_4): 1-26.

Von Stetina, Jessica R., Susanne Tranguch, Sudhansu K. Dey, Laura A. Lee, Byeong Cha, et Daniela Drummond-Barbosa. 2008. Alpha-Endosulfine Is a Conserved Protein Required for Oocyte Meiotic Maturation in Drosophila. Development (Cambridge, England) 135 (22): 3697-3706.

Vozdova, Miluse, Eva Oracova, Katerina Kasikova, Petra Prinosilova, Roman Rybar, Vera Horinova, Renata Gaillyova, et Jiri Rubes. 2013. Balanced Chromosomal Translocations in Men: Relationships among Semen Parameters, Chromatin Integrity, Sperm Meiotic Segregation and Aneuploidy. Journal of Assisted Reproduction and Genetics 30 (3): 391-405.

World Health Organization: WHO laboratory manual for the examination and processing of human semen. Fifth ed. Cambridge University Press, 2010.

Xie, Chong, Xiangfeng Chen, Yulin Liu, Zhengmu Wu, et Ping. 2017. Multicentre Study of Genetic Abnormalities Associated with Severe Oligospermia and Non-Obstructive Azoospermia. The Journal of International Medical Research. 46(1):107-114

Zhang, H.G., R.X. Wang, L.L. Li, W.T. Sun, H.Y. Zhang, et R.Z. Liu. 2015. Male carriers of balanced reciprocal translocations in Northeast China: sperm count, reproductive performance, and genetic counseling. Genetics and Molecular Research 14 (4): 18792-98.

Zhang, Qing, Koichiro Shimoya, Yukinibu Ohta, Rika Chin, Kumiko Tenma, Shigeyuki Isaka, Hitomi Nakamura, Masayasu Koyama, Chihiro Azuma, et Yuji Murata. 2002. Detection of Fractalkine in Human Seminal Plasma and Its Role in Infertile Patients. Human Reproduction (Oxford, England) 17 (6): 1560-64.

Declaration: The authors report no financial or commercial conflicts of interest. 
Table 1 Semen characteristics in the various translocation types and control group

\begin{tabular}{llll}
\hline & CTL & RCT & ROBT \\
\hline$n$ & 105 & 81 & 63 \\
\hline Male age (years) & & & \\
& $36.1 \pm 4.7$ & $35.8 \pm 5.1$ & $35.7 \pm 5.5$ \\
& $35.6(33.3-$ & $34.9(32.3-$ & $35.3(32.0-$ \\
& $38.1)$ & $38.5)$ & $38.7)$ \\
\hline Sexual abstinence (days) & $3.0 \pm 1.0$ & $3.1 \pm 0.9$ & $2.9 \pm 1.1$ \\
& $3.0(2.0-4.0)$ & $3.0(2.0-4.0)$ & $3.0(2.0-$ \\
& & & $4.0)$ \\
\hline
\end{tabular}

Before migration

\begin{tabular}{llll}
\hline Seminal volume $(\mathrm{ml})$ & $3.5 \pm 1.3$ & $3.2 \pm 1.4$ & $3.2 \pm 1.3$ \\
& $3.5(2.5-4.2)$ & $3.0(2.0-4.0)$ & $\begin{array}{l}3.5(2.0- \\
4.0)\end{array}$ \\
& & & $10.8 \pm 14.0$ \\
\hline Sperm concentration $\left(\times 10^{6} / \mathrm{ml}\right)$ & $90.8 \pm 58.7$ & $49.0 \pm 50.1$ & $5.0(0.6-$ \\
& $88.0(40.0-$ & $32.0(4.5-$ & $15.0)$ \\
\hline Total sperm count $\left(\times 10^{6}\right)$ & $150.0)$ & $92.0)$ & $32.0 \pm 39.9$ \\
& $301.7 \pm 211.8$ & $159.2 \pm 189.0$ & $12.6(3-$ \\
& $300.0(135.0-$ & $99.0(10-$ & $49.5)$ \\
\hline Progressively motile sperm $(\%)$ & $450.0)$ & $245.0)$ & $14.6 \pm 12.7$ \\
& $33.2 \pm 6.6$ & $22.1 \pm 12.5$ & $15.0(1.0-$ \\
& $30.0(20.0-$ & $25.0(12.5-$ & $21.2)$ \\
\hline
\end{tabular}

After migration

\begin{tabular}{llll}
\hline Total number of progressive & $30.4 \pm 36.7$ & $10.5 \pm 20.9$ & $0.7 \pm 1.4$ \\
spermatozoa $\left(\times 10^{6}\right)$ & $18.3(8.8-$ & $2.24(0.2-$ & $0.13(0-0.6)$ \\
& $36.2)$ & $8.8)$ & \\
\hline
\end{tabular}

Data are presented as mean $\pm \mathrm{SD}$, followed by median (interquartile range).

Sperm concentration and total sperm count: difference was significant $(P<0.0001)$ between RCT and ROBT as also between RCT or ROBT and CTL $(P<0.0001)$. Progressive sperm motility: difference was significant $(P<0.001)$ between RCT and ROBT as also between

RCT and CTL $(P<0.001)$ or ROBT and CTL $(P<0.0001)$. Total number of progressive spermatozoa retrieved after preparation:

difference was significant $(P<0.001)$ between RCT and ROBT as also between RCT or ROBT and CTL $(P<0.0001)$.

$\mathrm{CTL}=$ control $; \mathrm{RCT}=$ reciprocal translocation; $\mathrm{ROBT}=$ Robertsonian translocation . 
Table 2 Listing of karyotypes and distances from breakpoints to centromeres for RCT translocation carriers according to NPS-ASP category

\begin{tabular}{|c|c|c|c|c|}
\hline $\begin{array}{l}\text { NPS-ASP } \\
\text { category }\end{array}$ & Karyotype & $\begin{array}{l}\text { CBP1 } \\
(\mathrm{Mb})\end{array}$ & CBP2 (Mb) & $\begin{array}{l}\text { NPS-ASP } \\
\text { value }\end{array}$ \\
\hline \multicolumn{5}{|l|}{ Very poor } \\
\hline Patient 1 & $46, \mathrm{XY}, \mathrm{t}(1 ; 15)(\mathrm{p} 36.1 ; \mathrm{q} 11.2)$ & 102.9 & 25.5 & 0.08 \\
\hline Patient 2 & $46, \mathrm{XY}, \mathrm{t}(1 ; 18)(\mathrm{p} 22 ; \mathrm{q} 21.1)$ & 35.2 & 5.6 & 0.24 \\
\hline Patient 3 & $46, X Y, t(1 ; 16)(p 33 ; q 23)$ & 76.2 & 59.8 & $1.10^{-3}$ \\
\hline Patient 4 & $46, \mathrm{XY}, \mathrm{t}(1 ; 7)(\mathrm{p} 21 ; \mathrm{p} 21)$ & 24.0 & 56.0 & $1.10^{-3}$ \\
\hline Patient 5 & $46, \mathrm{XY}, \mathrm{t}(1 ; 17)(\mathrm{q} 21 ; \mathrm{q} 12)$ & 23.8 & 61.5 & 0.18 \\
\hline Patient 6 & $46, \mathrm{XY}, \mathrm{t}(1 ; 10)(\mathrm{p} 22.3 ; \mathrm{q} 22.3)$ & 38.3 & 4.2 & 0.50 \\
\hline Patient 7 & $46, X Y, t(2 ; 9)(p 24 ; q 33)$ & 75.2 & 7.9 & $1.10^{-3}$ \\
\hline Patient 8 & $46, \mathrm{XY}, \mathrm{t}(3 ; 14)(\mathrm{q} 13.2 ; \mathrm{p} 12)$ & 21.4 & 138.7 & $1.10^{-3}$ \\
\hline Patient 9 & $46, X Y, t(4 ; 8)(q 33 ; q 21)$ & 120.6 & 26.8 & 0.03 \\
\hline Patient 10 & $46, \mathrm{XY}, \mathrm{t}(5 ; 14)(\mathrm{q} 11.1 ; \mathrm{p} 12)$ & 1.2 & 73.7 & $1.10^{-3}$ \\
\hline Patient 11 & $46, X Y, t(5 ; 9)(q 34 ; q 31)$ & 115.8 & 1.6 & 0.50 \\
\hline Patient 12 & $46, X Y, t(5 ; 6)(p 15.1 ; q 23)$ & 39.2 & 45.8 & 0.45 \\
\hline Patient 13 & $46, X Y, t(6 ; 15)(p 12 ; q 12)$ & 9.4 & 33.8 & $1.10^{-3}$ \\
\hline Patient 14 & $46, \mathrm{XY}, \mathrm{t}(6 ; 10)(\mathrm{p} 21.1 ; \mathrm{q} 24)$ & 17.6 & 4.3 & 0.07 \\
\hline Patient 15 & $46, \mathrm{XY}, \mathrm{t}(8 ; 19)(\mathrm{q} 24.1 ; \mathrm{q} 13.3)$ & 76.9 & 104.5 & $1.10^{-3}$ \\
\hline Patient 16 & $46, X Y, t(8 ; 18)(q 23 ; q 22)$ & 66.4 & 15.3 & $1.10^{-3}$ \\
\hline Patient 17 & $46, X Y, t(9 ; 14)(p 21 ; q 11.2)$ & 9.3 & 12.7 & 0.31 \\
\hline Patient 18 & $46, \mathrm{XY}, \mathrm{t}(9 ; 14)(\mathrm{q} 12 ; \mathrm{p} 11.2)$ & 22.4 & 61.2 & $1.10^{-3}$ \\
\hline Patient 19 & $46, X Y, t(9 ; 17)(p 13 ; q 11.2)$ & 11.9 & 5.9 & 0.42 \\
\hline Patient 20 & $46, \mathrm{XY}, \mathrm{t}(10 ; 20)(\mathrm{q} 26.3 ; \mathrm{p} 11.1)$ & 104.2 & 35.5 & 0.04 \\
\hline Patient 21 & $46, \mathrm{XY}, \mathrm{t}(11 ; 22)(\mathrm{q} 25 ; \mathrm{q} 11.2)$ & 79.2 & 0.9 & 0.22 \\
\hline Patient 22 & $46, X Y, t(11 ; 17)(q 22 ; q 23)$ & 50.1 & 4.8 & $1.10^{-3}$ \\
\hline Patient 23 & $46, \mathrm{XY}, \mathrm{t}(15 ; 16)(\mathrm{p} 11.2 ; \mathrm{q} 21)$ & 6.7 & 4.3 & 0.04 \\
\hline Patient 24 & $46, \mathrm{XY}, \mathrm{t}(15 ; 17)(\mathrm{q} 15 ; \mathrm{p} 11.2)$ & 23.5 & 24.4 & 0.24 \\
\hline Patient 25 & $46, \mathrm{XY}, \mathrm{t}(16 ; 18)(\mathrm{q} 11.2 ; \mathrm{p} 11.2)$ & 6.2 & 5.0 & 0.08 \\
\hline Patient 26 & $46, \mathrm{XY}, \mathrm{t}(17 ; 19)(\mathrm{q} 11.2 ; \mathrm{q} 13.4)$ & 4.8 & 28.7 & 0.01 \\
\hline Patient 27 & $46, \mathrm{XY}, \mathrm{t}(17 ; 18)(\mathrm{p} 12 ; \mathrm{q} 21.1)$ & 10.6 & 37.4 & 0.07 \\
\hline $\begin{array}{l}\text { Patient } 28 \\
\text { Poor }\end{array}$ & $46, \mathrm{XY}, \mathrm{t}(18 ; 21)(\mathrm{p} 11.1 ; \mathrm{q} 11.1)$ & 0.9 & 52.0 & $1.10^{-3}$ \\
\hline Patient 29 & $46, X Y, t(1 ; 5)(q 21 ; q 31.2)$ & 23.8 & 28.0 & 0.90 \\
\hline Patient 30 & $46, X Y, t(2 ; 21)(q 32 ; q 21)$ & 96.9 & 41.3 & 0.57 \\
\hline Patient 31 & $46, \mathrm{XY}, \mathrm{t}(2 ; 16)(\mathrm{q} 14.3 ; \mathrm{q} 21)$ & 32.8 & 18.3 & 0.96 \\
\hline Patient 32 & $46, X Y, t(3 ; 19)(p 25 ; q 13.1)$ & 78.4 & 8.6 & 0.67 \\
\hline Patient 33 & $46, X Y, t(4 ; 22)(q 10 ; q 10)$ & 1.2 & 2.6 & 0.92 \\
\hline Patient 34 & $46, X Y, t(4 ; 6)(p 16 ; p 21)$ & 44.7 & 36.1 & 1.00 \\
\hline $\begin{array}{l}\text { Patient } 35 \\
\text { Fair }\end{array}$ & $46, X Y, t(11 ; 22)(q 23.23 ; q 11.2)$ & 59.8 & 28.7 & 0.90 \\
\hline Patient 36 & $46, X Y, t(1 ; 16)(q 32 ; q 22)$ & 81.6 & 5.1 & 1.80 \\
\hline
\end{tabular}




\begin{tabular}{|c|c|c|c|c|}
\hline Patient 37 & $46, X Y, t(1 ; 13)(q 12 ; q 34)$ & 10.8 & 5.5 & 2.24 \\
\hline Patient 38 & $46, \mathrm{XY}, \mathrm{t}(1 ; 5)(\mathrm{p} 22 ; \mathrm{p} 13)$ & 35.2 & 37.4 & 2.40 \\
\hline Patient 39 & $46, X Y, t(1 ; 5)(p 36 ; p 14)$ & 111.0 & 38.0 & 3.60 \\
\hline Patient 40 & $46, X Y, t(2 ; 7)(p 14 ; q 21.3)$ & 27.0 & 11.7 & 4.80 \\
\hline Patient 41 & $46, X Y, t(3 ; 17)(q 25 ; q 23)$ & 63.8 & 45.4 & 2.32 \\
\hline Patient 42 & $46, \mathrm{XY}, \mathrm{t}(4 ; 11)(\mathrm{p} 15.2 ; \mathrm{q} 21)$ & 25.9 & 75.0 & 2.10 \\
\hline Patient 43 & $46, X Y, t(5 ; 11)(q 32 ; q 25)$ & 98.8 & 37.4 & 1.44 \\
\hline Patient 44 & $46, \mathrm{XY}, \mathrm{t}(5 ; 7)(\mathrm{p} 15.1 ; \mathrm{q} 32)$ & 39.2 & 36.9 & 2.10 \\
\hline Patient 45 & $46, X Y, t(5 ; 21)(q 15 ; q 22.2)$ & 46.9 & 50.2 & 2.10 \\
\hline Patient 46 & $46, \mathrm{XY}, \mathrm{t}(6 ; 8)(\mathrm{q} 11 ; \mathrm{q} 11)$ & 1.2 & 94.8 & 2.40 \\
\hline Patient 47 & $46, X Y, t(6 ; 22)(q 25.3 ; q 13.31)$ & 97.3 & 7.2 & 2.60 \\
\hline Patient 48 & $46, X Y, t(6 ; 8)(q 27 ; q 24.1)$ & 106.8 & 36.9 & 3.36 \\
\hline Patient 49 & $46, X Y, t(6 ; 14)(q 24.2 ; p 11.2)$ & 83.2 & 24.7 & 3.92 \\
\hline Patient 50 & $46, \mathrm{XY}, \mathrm{t}(6 ; 15)(\mathrm{q} 11 ; \mathrm{p} 11)$ & 1.2 & 42.6 & 4.95 \\
\hline Patient 51 & $46, X Y, t(8 ; 11)(p 23.3 ; p 11.1)$ & 44.5 & 72.3 & 4.18 \\
\hline $\begin{array}{l}\text { Patient } 52 \\
\text { Good }\end{array}$ & $46, \mathrm{XY}, \mathrm{t}(12 ; 18)(\mathrm{p} 11.2 ; \mathrm{p} 11.2)$ & 5.9 & 70.0 & 1.40 \\
\hline Patient 53 & $46, X Y, t(1 ; 4)(p 34.1 ; q 35.2)$ & 79.5 & 5.5 & 33.39 \\
\hline Patient 54 & $46, X Y, t(2 ; 9)(p 24.3 ; p 23)$ & 78.9 & 36.1 & 5.85 \\
\hline Patient 55 & $46, \mathrm{XY}, \mathrm{t}(2 ; 14)(\mathrm{q} 24 ; \mathrm{q} 23)$ & 69.0 & 7.2 & 7.68 \\
\hline Patient 56 & $46, \mathrm{XY}, \mathrm{t}(2 ; 14)(\mathrm{p} 13 ; \mathrm{q} 11.2)$ & 21.5 & 39.7 & 8.28 \\
\hline Patient 57 & $46, X Y, t(3 ; 6)(q 29 ; q 27)$ & 104.2 & 35.5 & 5.25 \\
\hline Patient 58 & $46, X Y, t(3 ; 15)(p 24 ; q 23)$ & 67.3 & 76.9 & 6.30 \\
\hline Patient 59 & $46, X Y, t(3 ; 10)(p 23 ; p 11.2)$ & 59.5 & 20.9 & 21.28 \\
\hline Patient 60 & $46, X Y, t(3 ; 5)(p 24.3 ; q 15)$ & 70.8 & 33.1 & 23.20 \\
\hline Patient 61 & $46, \mathrm{XY}, \mathrm{t}(3 ; 8)(\mathrm{q} 26.1 ; \mathrm{q} 13)$ & 73.2 & 106.8 & 29.12 \\
\hline Patient 62 & $46, \mathrm{XY}, \mathrm{t}(4 ; 10)(\mathrm{q} 31.1 ; \mathrm{p} 15)$ & 90.1 & 79.2 & 9.20 \\
\hline Patient 63 & $46, \mathrm{XY}, \mathrm{t}(4 ; 6)(\mathrm{q} 32 ; \mathrm{q} 22)$ & 112.5 & 10.8 & 17.92 \\
\hline Patient 64 & $46, X Y, t(5 ; 11)(q 35.1 ; q 24)$ & 126.3 & 50.2 & 5.18 \\
\hline Patient 65 & $46, X Y, t(5 ; 18)(q 34 ; q 21.1)$ & 115.8 & 25.5 & 5.60 \\
\hline Patient 66 & $46, X Y, t(5 ; 9)(p 15.2 ; p 23)$ & 36.0 & 51.1 & 8.40 \\
\hline Patient 67 & $46, \mathrm{XY}, \mathrm{t}(5 ; 14)(\mathrm{p} 15.1 ; \mathrm{q} 24)$ & 39.2 & 9.1 & 12.15 \\
\hline Patient 68 & $46, X Y, t(5 ; 6)(q 33 ; q 23)$ & 106.5 & 0.6 & 16.90 \\
\hline Patient 69 & $46, X Y,(5 ; 17)(q 35 ; q 25)$ & 126.3 & 22.7 & 33.60 \\
\hline Patient 70 & $46, X Y, t(5 ; 10)(p 13 ; p 15)$ & 12.7 & 28.7 & 53.42 \\
\hline Patient 71 & $46, X Y,(6 ; 22)(p 25 ; p 12)$ & 57.4 & 11.0 & 7.00 \\
\hline Patient 72 & $46, X Y, t(6 ; 13)(p 22 ; q 13)$ & 38.2 & 46.9 & 128.80 \\
\hline Patient 73 & $46, \mathrm{XY}, \mathrm{t}(7 ; 9)(\mathrm{p} 22 ; \mathrm{p} 13)$ & 56.2 & 11.9 & 14.14 \\
\hline Patient 74 & $46, X Y, t(8 ; 9)(q 23 ; p 23)$ & 16.4 & 28.8 & 51.97 \\
\hline Patient 75 & $46, \mathrm{XY}, \mathrm{t}(8 ; 16)(\mathrm{q} 11.2 ; \mathrm{q} 12)$ & 6.2 & 11.7 & 76.16 \\
\hline Patient 76 & $46, X Y, t(10 ; 11)(q 22 ; p 15)$ & 36.1 & 31.6 & 12.60 \\
\hline Patient 77 & $46, X Y, t(10 ; 14)(p 12 ; q 21)$ & 16.7 & 6.4 & 33.12 \\
\hline Patient 78 & $46, X Y, t(11 ; 22)(q 23 ; q 11)$ & 62.1 & 5.9 & 16.80 \\
\hline Patient 79 & $46, \mathrm{XY}, \mathrm{t}(11 ; 22)(\mathrm{q} 22,3 ; \mathrm{q} 13.3)$ & 53.0 & 4.9 & 48.00 \\
\hline Patient 80 & $46, \mathrm{XY}, \mathrm{t}(12 ; 18)(\mathrm{p} 11.2 ; \mathrm{q} 21.1)$ & 5.9 & 42.8 & 76.00 \\
\hline Patient 81 & $46, X Y, t(13,18)(q 31 ; q 22)$ & 69.1 & 73.7 & 20.16 \\
\hline
\end{tabular}

NPS-ASP = number of progressive spermatozoa retrieved after sperm preparation; CBP1 = centromere breakpoint distance 1 ; CBP2 = centromere breakpoint distance 2 . 
Figure 1 Sperm characteristics in the control group (CTL), reciprocal translocation (RCT) and Robertsonian translocation (ROBT) carriers. (A) Percentage of normozoospermic men in the three groups (sperm morphology excluded). (B) Patients were stratified according to their translocation and to NPS-ASP categories. Good NPSASP $\left(\geq 5 \times 10^{6}\right)$, fair NPS-ASP $\left(>1 \times 10^{6}\right.$ to $\left.<5 \times 10^{6}\right)$, poor NPS-ASP $\left(>0.5 \times 10^{6}\right.$ to $\left.\leq 1 \times 10^{6}\right)$ and very poor NPS-ASP $\left(\leq 0.5 \times 10^{6}\right)$. NPS-ASP $=$ number of progressive spermatozoa retrieved after sperm preparation.

Figure 2 Proportion of good, fair, poor, and very poor NPS-ASP values for each type of Robertsonian translocation. These rearrangements originate through the translocation of acrocentric chromosomes $(13,14,15,21,22)$. Rare translocations comprise $(13 q ; 21 q)-n=1,(13 q ; 15 q)-n=4,(14 q ; 15 q)-n=1,(14 q ; 22 q)-n=1,(15 q ; 21 q)-n$ $=1,(15 q ; 22 q)-n=1,(21 q ; 22 q)-n=1$. NPS-ASP categories defined as good $\left(\geq 5 \times 10^{6}\right)$, fair $\left(>1 \times 10^{6}\right.$ to $\left.<5 \times 10^{6}\right)$, poor NPS-ASP $\left(>0.5 \times 10^{6}\right.$ to $\left.\leq 1 \times 10^{6}\right)$ and very poor $\left(\leq 0.5 \times 10^{6}\right)$. NPS-ASP $=$ number of progressive spermatozoa retrieved after sperm preparation. 
A

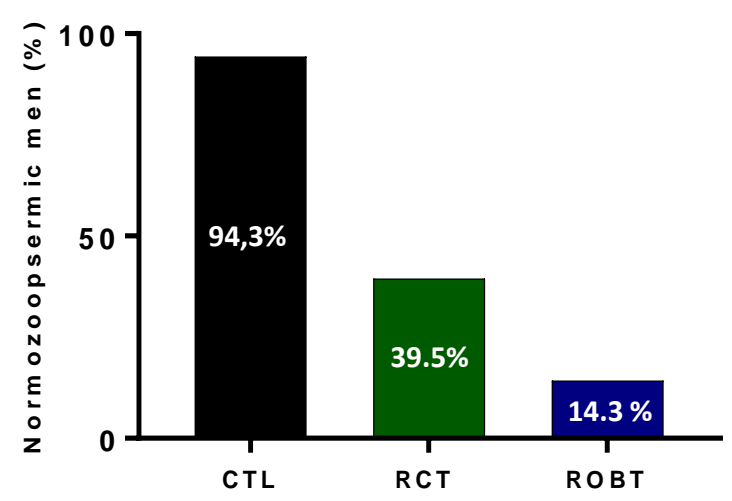

B

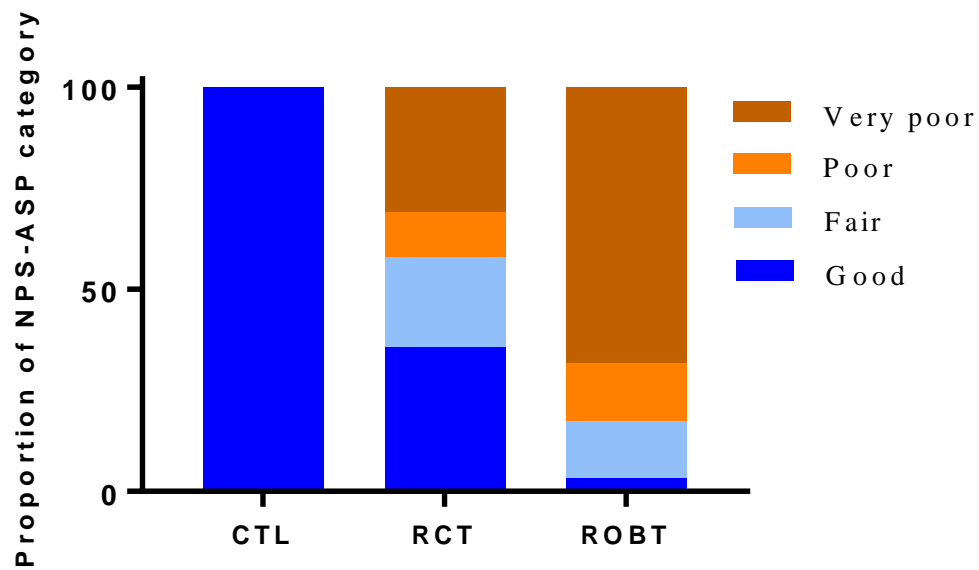




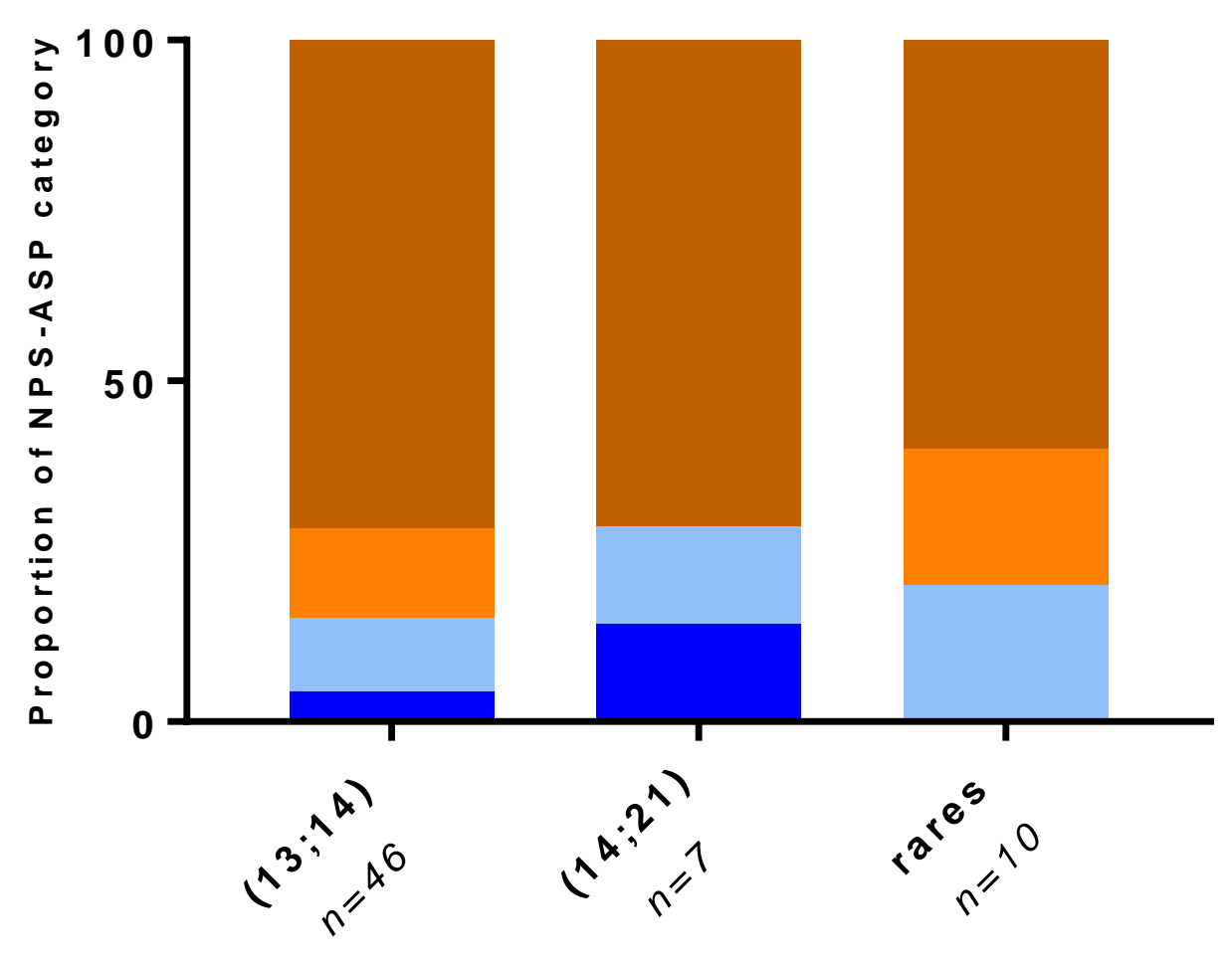

Very poor

Poor

\section{Fair}

- Good 